\title{
Психомогия безопасности
}

\section{УДК 159.9}

\section{Проблема психологической безопасности обучающихся в образовательном пространстве высшей школы}

\section{The problem of psychological safety of students in the educational space of higher education}

Ничипоренко Н.П., ФГБНУ «Институт педагогики, психологии и социальных проблем», nichiporenko.n@yandex.ru

Хусаинова С.В., Институт педагогики, психологии и социальных проблем, иs@ірріsр.rи

Nichiporenko N., Institute of Pedagogy, Psychology and Social Problems, nichiporenko.n@yandex.ru

Khusainova S., Institute of Pedagogy, Psychology and Social Problems, us@ippisp.ru

DOI: $10.51379 / \mathrm{KPJ} .2021 .150 .6 .034$

Статья выполнена по государственному заданию № 0599-2019-0003 «Проблема отклоняющегося поведения в системе современного человековедения».

Ключевые слова: образовательная среда, психологическое здоровье, психологическая безопасность, студенты высшей школь, негативные психические состояния, депрессивность.

Keywords: educational environment, psychological health, psychological safety, high school students, negative mental state, depression.

Аннотация. Статья посвящена проблеме психологической безопасности образовательного пространства высшей иколь, в частности, - исследованию удовлетворенности образовательной средой студентов гуманитарных специиальностей. Актуальность темы обусловлена необходимостью проектирования условий, способствующих сохранению психического и психологического здоровья молодежи. Целью нашего исследования являлся анализ психологического описания характеристик в образовательном пространстве высшей школь, значимых с точки зрения психологической безопасности обучающихся. В данном исследовании изучены взаимосвязи характеристик образовательной среды (позитивные переживания интереса, радости, удовлетворенности, и выраженности негативных эмоций страха, гнева и обиды) с уровнем депрессивности студентов. В статье анализируются результаты студентов высших учебных заведений гуманитарного профиля Республики Татарстан (выборка 7383 студента). В ходе исследования методом анкетирования изучались параметры образовательной среды, влияющие на психологическую безопасность личности эмоциональное отношение к обучению и удовлетворенность образовательной средой. Данное исследование предназначено для педагогов психологов, преподавателей и заинтересованных лии в развитии психологически безопасного образовательного пространства высшей школь. Материаль исследования могут быть использованы при организации и проведении мероприятий по психологической профилактике и сопровождению процессов адаптации студентов высших и средних учебных заведений.

Abstract. The article is devoted to the problem of psychological safety of the educational space of higher education, in particular, to the study of satisfaction with the educational environment of students of humanitarian specialties. The relevance of the topic is due to the need to design conditions conducive to the preservation of mental and psychological health of young people. The purpose of our study was to analyze the psychological description of characteristics in the educational space of higher education, which are significant from the point of view of the psychological safety of students. This study investigated the relationship between the characteristics of the educational environment (positive experiences of interest, joy, satisfaction, and the severity of negative emotions of fear, anger and resentment) with the level of students' depression. The article analyzes the results of students of higher educational institutions of the 
humanitarian profile of the Republic of Tatarstan (sample of 7383 students). In the course of the study, the parameters of the educational environment that affect the psychological safety of an individual - emotional attitude to learning and satisfaction with the educational environment - were studied using the questionnaire method. This study is intended for educational psychologists, teachers and those interested in the development of a psychologically safe educational space for higher education. The research materials can be used in the organization and implementation of measures for psychological prevention and support of the adaptation processes of students of higher and secondary educational institutions.

Введение. Важной составляющей учебного процесса вуза является создание безопасной образовательной среды и обеспечение условий, благоприятных для развития личности. Фокусирование на выявлении социальнопсихологических компонентов образовательной среды гуманитарного ВУЗа, связанных с негативными психическими состояниями студентов позволяют выявить психологические маркеры психологической безопасности личности.

Безопасность личности - характеристика отношений, неразрывно связанная с эмоциональными компонентами в виде переживания защищенности, спокойствия, комфорта. Далее мы будем исходить из позиции, что безопасность - характеристика отношений субъекта и среды, для рассмотрения которой важны два ракурса: психологическая безопасность личности в среде и психологическая безопасность среды для личности. Эти же характеристики являются основными переменными в модели психологической безопасности образовательной среды в работах И.А. Баевой [2;3]. В более широком ключе определяет феномен безопасности Зинченко Ю.П. - как деятельность конкретных социальных субъектов и отношений между ними, как сферу, в которой функционирует и развивается общественное, групповое и индивидуальное сознание [6].

Основные исследования российских авторов по данной тематике сконцентрированы в области безопасности школы [1;2], колледжей [3] и немного затрагивают систему высшего образования [5].

Баева И.А. рассматривая основные компоненты психологической безопасности образовательного пространства, определяет, что «отношение к образовательной среде, удовлетворенность ее основными характеристиками и защищенность от психологического насилия являются опорными и позволяют опираться на них при составлении опросников и анкет. Параметрами оценки удовлетворенности образовательной среды у педагогов и студентов являются следующие характеристики личности: взаимоотношение с учителями и учениками; возможность высказывать свою точку зрения; уважительное отношение к себе; сохранение личного достоинства; возможность обратиться за помощью; возможность проявлять инициативу; активность; учет личных проблем и затруднений; эмоциональный комфорт; внимание к просьбам и предложениям; помощь в выборе собственного решения» [3].

Андронникова О.О., компонентами технологической модели безопасной образовательной среды считает позитивное отношение, удовлетворенность отдельными составляющими образовательной среды, переживание субъективного чувства благополучия, индекс психологической безопасности (защищенности от психологического насилия), референтную значимость, личностно-доверительное общение, диалог и сотрудничество. Критериями психологической безопасности образовательной среды являются: отсутствие проявлений психологического насилия во взаимодействии участников образовательного процесса, удовлетворение основных потребностей в личностно-доверительном общении, укрепление психического здоровья, предотвращение угроз для развития личности, организация условий, обеспечивающих сохранение и развитие личности [1].

В зарубежных исследованиях обосновано влияние образовательной среды на мотивацию и самооценку обучающихся, степень адаптации к образовательной среде, устойчивое позитивное психологическое состояние студентов. Также показано влияние на уровень адаптации различных стресс-факторов - учебной нагрузки, проблем в учебе, отношений с родителями, семейных конфликтов, межличностной агрессии, социального климата [9;13].

Нами было проведено исследование, в котором методологическую основу составили положения и концепции Баевой И.А. Зинченко Ю.П., Мясищева В.Н., Хусаиновой С.В. и подходы отечественных психологов к описанию феномена безопасности через категории деятельности, сознания и отношений субъекта с миром $[2 ; 6 ; 11 ; 12]$. Концепция отношений В.Н. 
Мясищева рассматривалась как общепсихологическая теоретическая основа современных исследований в области клинической психологии (объясняющая этиопатогенетические механизмы психической адаптации в норме и при ее нарушениях) [7]. Базовый конструкт данной концепции - субъект отношений, личность как система и многообразие отношений человека к окружающей действительности [8]. Психологические отношения при этом понимаются как «щелостная система индивидуальных, избирательных, сознательных связей личности с различными сторонами объективной действительности» [11].

Роль нарушенных отношений в патогенезе неврозов позволяет анализировать компоненты социальной среды во взаимосвязи с разного рода отклонениями психического развития [10]. В нашем исследовании депрессивность диагностируется как невротическое состояние личности, затрагивающее высшие процессы волевого регулирования, патогенез которого протекает при доминирующей роли эмоций. «Невроз - это болезнь, возникающая вследствие конфликта человека с окружающей его действительностью, конфликта, разрушающего его социальные связи, изолирующего его. ... Чаще всего невроз возникает на почве столкновения желаний личности и действительности, которая их не удовлетворяет. Чем выше претензии личности, тем больше поводов для конфликтов» [10, с.55-56].

Маркерами изучения психологической безопасности образовательного пространства могут выступать эмоциональные состояния (интерес, радость, удовлетворение, страх, гнев, обида) и психические расстройства (депрессивность). В нашем исследовании в качестве маркеров рассматривается депрессивность и характеристики образовательной среды (позитивные и негативные).

Взаимосвязи депрессивности других личностных характеристик в образовательной среде описаны в исследовании Briere F.N. [14]: «подростки, посещающие среднюю школу с лучшей социально-образовательной средой, имеют меньший риск развития депрессивных симптомов, что говорит о важности изучения образовательной среды и ее протекционного потенциала» [13;14,15,].

Целью нашего исследования являлся анализ психологического описания характеристик образовательном пространстве высшей школы, значимых с точки зрения психологической безопасности личности.
Материаль и методы исследования. При выборе методов мы руководствовались следующими критериями: применимость в условиях массового обследования (скрининга) и возможность сочетать потенциал количественного и качественного анализа. Методики исследования: 1) шкала оценки депрессии В. Зунга [4]; 2) анкета, разработанная сотрудниками отдела мониторинга Ресурсного центра координации деятельности психологических служб Республики Татарстан «Ориентир» (О.А. Самаркин, Р.Н. Хакимзянов), из которой в данном исследовании анализировались семь вопросов, выявляющих отношение студентов к образовательной среде.

В исследовании приняли участие 7383 студента различных специальностей ведущих гуманитарных вузов РТ: Казанский федеральный университет (в том числе институт социальнофилософских наук и массовых коммуникаций (1235 чел.), институт международных отношений (1584 чел.), институт психологии и образования (850 чел.), институт филологии и межкультурной коммуникации (1380 чел.)); Набережночелнинский государственный педагогический университет (946 чел.); Казанская государственная консерватория (354 чел.); Казанский государственный институт культуры (1034 чел.).

Статистическая обработка результатов исследования проводилась с использованием корреляционного анализа (метод Пирсона).

Результатьл исследования. Ответы респондентов были проанализированы в два этапа: подсчитывались показатели положительных ответов по каждому вопросу анкеты (ответили «да» или «скорее да»), затем методом корреляционного анализа (коэффициент Пирсона) определялась количественная мера взаимосвязи каждого вопроса анкеты с показателем депрессивности. Депрессивность высоко коррелирует со всеми изученными социально-психологическими характеристиками образовательной среды (все 7 значений коэффициентов корреляции имеют уровень значимости $\mathrm{p}<0.001)$. Результаты по отдельным вопросам анкеты и их взаимосвязь с депрессивностью представлены в таблице 1.

Эмоциональное отношение к обучению. Данный параметр психологической безопасности в нашем исследовании отражает эмоциональный компонент отношения студентов к обучению: позитивные переживания интереса, радости, удовлетворенности, и выраженность негативных эмоций страха, гнева и обиды. Как показывают результаты, чуть больше половины студентов 
(около 60\%) демонстрируют положительно окрашенное эмоциональное отношение к процессу обучения и отношениям с другими студентами и преподавателями. Корреляции данной группы вопросов с депрессивностью высоки и носят обратный характер $(\mathrm{r}=-0.37, \mathrm{r}=$ $-0.38 . \mathrm{r}=-0.35)$.

Таблица 1. - Результать исследования удовлетворенности образовательной средой в связи с депрессивностью

\begin{tabular}{|c|c|c|}
\hline № & Формулировка вопроса анкеты & $\begin{array}{l}\text { Депрессивность } \\
(\mathrm{p} \leq 0,0001)\end{array}$ \\
\hline \multicolumn{3}{|c|}{ Эмоциональное отношение к обучению } \\
\hline 1 & Обучение приносит мне радость и удовлетворение & $\mathrm{r}=-0.38^{\mathrm{x}}$ \\
\hline 2 & Свое обучение в вузе я считаю интересным & $\mathrm{r}=-0.37$ \\
\hline 3 & $\begin{array}{l}\text { В институте я редко испытываю отрицательные эмоции (страх, гнев, обида), } \\
\text { связанные с учебой, отношениями с другими студентами и преподавателями }\end{array}$ & $\mathrm{r}=-0.35$ \\
\hline \multicolumn{3}{|c|}{ Удовлетворенность образовательной средой } \\
\hline 4 & Расписание занятий дает мне возможность избежать сильного утомления & $\mathrm{r}=-0.29$ \\
\hline 5 & $\begin{array}{l}\text { Я имею возможность отказаться от участия в мероприятиях, которые мне не } \\
\text { интересны }\end{array}$ & $\mathrm{r}=-0.19$ \\
\hline 6 & У меня есть возможность открыто высказывать свою позицию, точку зрения & $\mathrm{r}=-0.34$ \\
\hline 7 & У меня всегда есть возможность получать поддержку и помощь педагогов & $\mathrm{r}=-0.37$ \\
\hline
\end{tabular}

Удовлетворенность образовательной средой. Этот параметр психологической безопасности характеризует степени свободы в обращении студентов с тремя различными факторами образовательной среды: возможность регулировать учебные нагрузки и избегать переутомления, возможность открыто высказывать свою точку зрения и рассчитывать на поддержку педагогов. Экологичность расписания оставляет желать лучшего - менее половины опрошенных $(40,1 \%)$ считают, что расписание занятий позволяет избежать переутомления. Данный комплекс характеристик отражает возможность студентов влиять на процесс обучения, а это - мощный фактор в профилактике бессилия, беспомощности и депрессивности.

Ocобое, значительное влияние на депрессивность имеет возможность студентов получать поддержку и помощь со стороны педагогов ( $\mathrm{r}=-0.37)$. Положительно оценили данный параметр $62,5 \%$ респондентов. Этот показатель говорит о том, что «помогающий потенциал» педагогического состава реализован явно недостаточно.

К сожалению, процессы, происходящие в последнее время в высшей школе, негативно сказываются на системе отношений основных субъектов образовательного процесса - педагогов и студентов. Сами преподаватели перегружены бесконечным редактированием рабочих программ в соответствии с постоянно меняющимися требованиями ФГОС, увеличены часы аудиторной, в том числе «голосовой» нагрузки, подготовка учебных и методических материалов для дистанционного обучения и проверка студенческих работ, выполненных дистанционно, занимает колоссальное количество времени, не поддающегося учету в составе учебной нагрузки преподавателя, заполнение электронных форм отчетности (ведение электронных журналов, подсчет рейтингов, заполнение электронных ведомостей) также требует времени.

Введение рейтинговой системы, цифровизация образования и ее натиск в период пандемии катастрофично сказываются на преобразовании культурного пространства высшей школы. Основным трендом, порожденным цифровизацией образования, становится неуклонное изменение системы отношений между субъектами образовательного пространства. Баланс отношений смещается в сторону «взаимодействия с компьютером», а разнообразный ролевой репертуар преподавателя постепенно замещается тьюторским функционалом. Контакт преподавателя и студента, который раныше был размещен в сфере межличностных отношений и служил основным источником профессиональной удовлетворенности преподавателей, теперь опосредован дистантными формами коммуникации. В отношениях преподавателя и студента появился третий участник - цифровая среда. И этот факт, стремительный, необратимый и неизбежный, преобразует образовательное пространство высшей школы, редуцируя его диалогичность и кардинально меняя его ментальность и культуру. 
Новизна исследования состоит в том, что на репрезентативной выборке (мониторинг имел практически сплошной характер) глубоко исследован локальный компонент психологической безопасности удовлетворенность образовательной средой - в связи с депрессивностью как эмоциональным маркером психологического здоровья личности.

Заключение. Проблема психологической безопасности образовательного пространства высшей школы, в настоящее время является одним из необходимых направлений исследований, так как с учетом полученных результатов опросов и скринингов, есть возможность найти область, в которой необходимо повысить удовлетворенность образовательной средой студентов. Необходимость сохранения психологического здоровья молодежи ведет за собой проектирование условий, способствующих гармонизации образовательного пространства. Выявленные характеристики позитивные переживания интереса, радости, удовлетворенности, и выраженности негативных эмоций страха, гнева и обиды в образовательном пространстве, явились ключевыми на данный момент, с точки зрения повышения психологической безопасности обучающихся. Нами в проведенном исследовании изучены взаимосвязи характеристик образовательной среды с уровнем депрессивности студентов. В ходе исследования методом анкетирования изучались параметры образовательной среды, влияющие на психологическую безопасность личности - эмоциональное отношение к обучению и удовлетворенность образовательной средой, где выявлено присутствие депрессивности у некоторых обучающихся, разрушающего их социальные связи и изолирующего их от сверстников. Для педагогов психологов, преподавателей и заинтересованных лиц в развитии психологически безопасного образовательного пространства высшей школы, использование в своей практической деятельности результатов нашего исследования, позволит наметить траекторию их будущей деятельности. Проведение дальнейших исследований в данном направлении позволит дать инструменты для разработки новых маршрутов организационной карты и проведения мероприятий по психологической профилактике и сопровождению студентов группы риска высших и средних учебных заведений.

\section{Лumepamypa:}

1. Андронникова О.О. Безопасность образовательной среды как условие сохранения физического и психологического здоровья участников образовательного процесса / О.О. Андронникова // СМАЛЬТА. - 2019. - № 1. - С. 5-14.

2. Баева И.А. Психологическая безопасность образовательной среды: как ее создать и измерить: сборник научных статей / И.А. Баева // Экопсихологические исследования-6: экология детства и психология устойчивого развития (Москва, 17-18 марта 2020 года); Психологический институт Российской академии образования Лаборатория экопсихологии развития и психодидактики. - Москва, 2020. - C. 280-284. - DOI: 10.24411/9999-044A-202000064

3. Баева И.А., Кондакова И.В. Психологическая безопасность образовательной среды в оценках педагогов и учащихся колледжей: сборник / И.А. Баева, И.В. Кондакова // Профилактика девиантного поведения детей и молодежи: региональные модели и технологии / Материалы Второй Международной научно-практической конференции (8-10 октября 2020 года); под научной ред. В.В. Коврова. - Симферополь: ИТ «АРИАЛ», 2020. - С. 213-221.

4. Барканова О.В. Методики диагностики эмоциональной сферы: gсихологический практикум / O.В. Барканова. Серия: Библиотека актуальной психологии. - Вып.2. - Красноярск: Литера-принт, 2009. $-237 \mathrm{c}$.
5. Бекоева М.И. Безопасная образовательная среда как фактор успешной познавательной деятельности студентов / М.И. Бекоева // Балтийский гуманитарный журнал. - 2017. - Т. 6. - № 4 (21). - С. 259-261.

6. Зинченко Ю.П. Методологические основы психологии безопасности / Ю.П. Зинченко // Национальный психологический журнал. - 2011. - № 2 (6). - C. 11-14.

7. Иовлев Б.В., Карпова Э.Б. Психология отношений. Концепция В.Н. Мысищева и медицинская психология / Б.В. Иовлев, Э.Б. Карпова. - СПб.: Сенсор, 1999. - 76 с

8. Карпова Э.Б., Исурина Г.Л., Журавлев А.Л. Психологическая концепция отношений В.Н. Мясищева: основы и содержание / Э.Б. Карпова, Г.Л. Исурина, А.Л. Журавлев // Психологический журнал. 2020. - Т. 41. - № 2. - С. 5-14.

9. Козлова О.В. Психология безопасности образовательной среды в некоторых зарубежных исследованиях начала XXI века / О.В. Козлова // Современная зарубежная психология. - 2012. - № 3. C. 62-70.

10. Мясищев В.Н. Личность и неврозы / В.Н. Мясищев. - Ленинград: Изд-во Ленингр. ун-та, 1960. $426 \mathrm{c}$.

11. Мясищев В.Н. Психология отношений: избранные психологические труды / В.Н. Мясищев; под ред. А.А. Бодалева. - М.: Изд-во Московского 
психолого-социального ин-та. - Воронеж: МОДЭК, 1995. $-356 \mathrm{c}$.

12. Хусаинова С.В. Внешнее влияние как фактор безопасности образовательной среды / С.В. Хусаинова // Научное мнение. - 2018. - № 1. - С. 85-92.

13. Bradshaw C.P., Waasdorp T.E., Debnam K.J., Johnson S.L. Measuring school climate in high schools: A focus on safety, engagement, and the environment // Journal of School Health. - 2014. - № 84 (9). - pp. 593604. DOI: $10.1111 /$ josh. 12186
14. Briere F.N., Pascal S., Dupere V., Janosz M. School Environment and Adolescent Depressive Symptoms: A Multilevel Longitudinal Study // Pediatrics. 2013. - № 131(3). - pp. 702-708.

15. Cornell D., Sheras P., Gregory A., Fan X. A Retrospective Study of School Safety Conditions in High Schools Using the Virginia Threat Assessment Guidelines Versus Alternative Approaches // School Psychology Quarterly. - 2009. - 24 (2). - pp. 119-129. DOI: 10.1037/a0016182

\section{References:}

1. Andronnikova OO Safety of the educational environment as a condition for preserving the physical and psychological health of participants in the educational process / O.O. Andronnikov // SMALTA. - 2019. - № 1. S. 5-14.

2. Baeva I.A. Psychological safety of the educational environment: how to create and measure it: collection of scientific articles / I.A. Baeva // Ecopsychological Research-6: Childhood Ecology and Psychology of Sustainable Development (Moscow, March 17-18, 2020); Psychological Institute of the Russian Academy of Education Laboratory of developmental ecopsychology and psychodidactics. - Moscow, 2020. - S. 280-284. - DOI: 10.24411 / 9999-044A-2020-00064

3. Baeva I.A., Kondakova I.V. Psychological safety of the educational environment in the assessments of teachers and college students: collection / I.A. Baeva, I. V. Kondakova // Prevention of deviant behavior in children and youth: regional models and technologies / Materials of the Second International Scientific and Practical Conference (October 8-10, 2020); under the scientific ed. V.V. Kovrov. - Simferopol: IT "ARIAL", 2020. - S. 213221.

4. Barkanova O.V. Methods for diagnosing the emotional sphere: psychological practice / O.V. Barkanov. Series: Library of Actual Psychology. - Issue 2. Krasnoyarsk: Litera-print, 2009. - 237 p.

5. Bekoeva M.I. Safe educational environment as a factor of successful cognitive activity of students / M.I. Bekoeva // Baltic Humanitarian Journal. - 2017. - T. 6. - № 4 (21). - S. 259-261.

6. Zinchenko Yu.P. Methodological foundations of safety psychology / Yu.P. Zinchenko // National psychological journal. - 2011. - № 2 (6). - S. 11-14.

7. Iovlev B.V., Karpova E.B. Psychology of relationships. V.N. Mysischeva and medical psychology / B.V. Iovlev, E.B. Karpov. - SPb.: Sensor, 1999. - 76 p.
8. Karpova E.B., Isurina G.L., Zhuravlev A.L. The psychological concept of relations by V.N. Myasishcheva: basics and content / E.B. Karpova, G.L. Isurina, A.L. Zhuravlev // Psychological journal. - 2020. - T. 41. - № 2. S. 5-14.

9. Kozlova O.V. Psychology of the safety of the educational environment in some foreign studies at the beginning of the XXI century / O.V. Kozlova // Modern foreign psychology. - 2012. - № 3. - S. 62-70.

10. Myasishchev V.N. Personality and neuroses / V.N. Myasishchev. - Leningrad: Publishing house Leningrad. University, 1960. - 426 p.

11. Myasishchev V.N. Psychology of relations: selected psychological works / V.N. Myasishchev; ed. A.A. Bodaleva. - M.: Publishing house of the Moscow Psychological and Social Institute. - Voronezh: MODEK, 1995. - $356 \mathrm{p}$.

12. Khusainova S.V. External influence as a safety factor of the educational environment / S.V. Khusainova // Scientific opinion. - 2018. - № 1. - P. 85-92.

13. Bradshaw C.P., Waasdorp T.E., Debnam K.J., Johnson S.L. Measuring school climate in high schools: A focus on safety, engagement, and the environment // Journal of School Health. - 2014. - № 84 (9). - pp. 593-604. Doi: 10.1111 / josh. 12186

14. Briere F.N., Pascal S., Dupere V., Janosz M. School Environment and Adolescent Depressive Symptoms: A Multilevel Longitudinal Study // Pediatrics. 2013. - № 131 (3). - pp. 702-708.

15. Cornell D., Sheras P., Gregory A., Fan X. A Retrospective Study of School Safety Conditions in High Schools Using the Virginia Threat Assessment Guidelines Versus Alternative Approaches // School Psychology Quarterly. - 2009. - 24 (2). - pp. 119-129. DOI: 10.1037 / a0016182

\subsubsection{1 - Общая психология, психология личности, история психологии}

\section{Сведения об авторах:}

Ничипоренко Надежда Павловна (г. Казань, Россия), кандидат психологических наук, доцент, старший научный сотрудник, ФГБНУ «Институт педагогики, психологии и социальных проблем», еmail: nichiporenko.n@yandex.ru

Хусаинова Светлана Владимировна (г. Казань, Россия), кандидат психологических наук, ведущий научный сотрудник, ФГБНУ «Институт педагогики, психологии и социальных проблем», еmail: sv_husainova@mail.ru 